\title{
Photochemical Hole Burning of $\mathrm{Sm}^{2+}$ in Sodium Borate Glasses Induced by Near-Infrared Femtosecond-Laser Irradiation
}

\author{
Koji FUJITA, Chikafumi YASUMOTO and Kazuyuki HIRAO \\ Department of Material Chemistry, Graduate School of Engineering, Kyoto University, Sakyo-ku, Kyoto-shi 606-8501
}

\author{
近赤外フェムト秒レーザー照射により誘起されたナトリウムホウ酸塩ガラスにおける \\ $\mathrm{Sm}^{2+}$ の光化学ホールバーニング \\ 藤田晃司·安本親文·平尾一之 \\ 京都大学大学院工学研究科材料化学専攻, 606-8501 京都市左京区吉田本町
}

\begin{abstract}
We report on photochemicall hole burning of $\mathrm{Sm}^{2+}$ in sodium borate glasses irradiated with femtosecondlaser pulses of $800 \mathrm{~nm}$ wavelength. The irradiation of $\mathrm{Sm}^{3+}$-doped sodium borate glasses with femtosecondlaser pulses causes electron-trapped $\mathrm{Sm}^{3+}$, i.e., $\mathrm{Sm}^{2+}$ and point defects such as an oxygen hole center and an electron trapped near $\mathrm{Na}^{+}$. The measurements of spectral hole burning were carried out for the ${ }^{5} D_{0^{-}}{ }^{7} F_{0}$ transition of $\mathrm{Sm}^{2+}$ using a DCMI dye laser. Photoionization hole burning is observed at $77 \mathrm{~K}$ to room temperature for the glasses exposed to femtosecond-laser pulses, and also for the glasses prepared by melting under reducing conditions. The hole-burning efficiency of $\mathrm{Sm}^{2+}$ produced by the photoinduced process is about twice higher than that by the thermal process. It is thought that the metastable $\mathrm{Sm}^{2+}$ ions and oxygen hole centers induced by femtosecond-laser irradiation are responsible for the observed phenomenon. We propose that the efficient photoionization hole burning is caused by the photostimulated recombination of the electron trapped by $\mathrm{Sm}^{3+}$ with the oxygen hole center.
\end{abstract}

[Received September 21, 2000; Accepted February 16, 2001]

\begin{abstract}
Key-words : Near-infrared femtosecond-laser pulses, Sodium borate glasses, Samarium ions, Persistent spectral hole burn-
\end{abstract} ing

1. Introduction

Interaction of radiation with matter attracts considerable attention in many areas of science since the discovery of the laser. In particular, vigorous investigations have been carried out into the interaction of laser radiation with glass, which is a key material in modern optical technology. The recent development of femtosecond-laser pulses with highenergy density has provided us with the unexplored potential for inducing photophysical and photochemical reactions in glass. The femtosecond-laser pulses can be used to rapidly and precisely deposit energy in solids. For instance, the light is absorbed by electrons, and the optical excitation is completed before the lattice is upset; the electrons transfer their excess energy to the lattice on a time scale of picoseconds, and micrometer-scale atomic displacement occurs on a time scale of nanoseconds. Besides, the strength of electric field of tightly focused $100 \mathrm{fs}$ pulses, the energy of which is $1 \mu \mathrm{J}$, can reach $\sim 100 \mathrm{TW} / \mathrm{cm}^{2}$, which is sufficient for inducing nonlinear optical effects in materials. Consequently, femtosecond pulses have an additional unique advantage in laser processing of transparent materials.

Recent observation that photoinduced permanent and metastable structural changes can be produced only near the beam focusing area inside transparent glasses with femtosecond-laser pulses ${ }^{1)-4)}$ has attracted great attention, because they can be applied to the fabrication of integrated circuits, photonic band gap materials, patterned grating in fibers, and three-dimensional optical memory. Of particular interest is internal microstructuring of transparent glasses, which is not accompanied by crack as observed with nanosecond laser pulses. One-photon excitation that is resonant with the intrinsic absorption of glass leads to the reaction in all the exposed areas adjacent to the glass surface, since the energy is deposited beneath the surface. In the case of the near-infrared femtosecond laser beam, on the other hand, the multiphoton excitation can induce the space-selective reaction in the vicinity of the focal point of the laser beam, where the pulse energy is sufficiently high.

In the present investigation, we examine photoinduced valence changes of samarium ions inside sodium borate glasses exposed to near-infrared femtosecond-laser pulses. Qiu et al.5),6) reported the reduction of $\mathrm{Sm}^{3+}$ to $\mathrm{Sm}^{2+}$ and the creation of point defects in a fluoroaluminate glass and a sodium aluminoborate glass using near-infrared femtosecond-laser pulses, and proposed that the multiphoton process of near-infrared radiation is responsible for the observed phenomenon. Our interest here is whether the glass structure around the photoreduced $\mathrm{Sm}^{3+}\left(\mathrm{Sm}^{2+}\right)$ is experiencing a combination of defect formation and structural relaxation. For this purpose, photoionization of $\mathrm{Sm}^{2+}$ is measured by means of spectral hole burning both for the glasses exposed to femtosecond-laser pulses and the glasses prepared by melting in reducing conditions. The sodium borate glasses were chosen as hosts because $\mathrm{Sm}^{3+}$ is reduced to $\mathrm{Sm}^{2+}$ during melting under reducing conditions. ${ }^{7)-9)}$ This makes it possible to compare the optical properties of $\mathrm{Sm}^{2+}$ created by the photoinduced process with those of $\mathrm{Sm}^{2+}$ formed by the thermal process.

\section{Experimental procedures}

Reagent-grade $\mathrm{Na}_{2} \mathrm{CO}_{3}, \mathrm{~B}_{2} \mathrm{O}_{3}$, and $\mathrm{Sm}_{2} \mathrm{O}_{3}$ powders were used to prepare glasses with $15 \mathrm{Na}_{2} \mathrm{O} \cdot 85 \mathrm{~B}_{2} \mathrm{O}_{3} \cdot 1.0 \mathrm{Sm}_{2} \mathrm{O}_{3}$ and $25 \mathrm{Na}_{2} \mathrm{O} \cdot 75 \mathrm{~B}_{2} \mathrm{O}_{3} \cdot 1.0 \mathrm{Sm}_{2} \mathrm{O}_{3}$ compositions in molar ratio. A $10 \mathrm{~g}$ batch composed of the raw materials was mixed thoroughly, and melted in a platinum crucible at $1100^{\circ} \mathrm{C}$ for $30 \mathrm{~min}$ in air. The melt was poured onto a stainless steel plate and cooled to room temperature in air. For comparison, we prepared the sodium borate glass with the identical composition by melting in a glassy carbon crucible at 1350 
${ }^{\circ} \mathrm{C}$ for 30 min under a $95 \% \mathrm{Ar}-5 \% \mathrm{H}_{2}$ atmosphere, which we will refer to in the following often as thermally reduced glass. The glass sample thus obtained was cut into a rectangular parallelepiped using a saw pasted with diamond powder, and the surfaces of the resultant glass sample were polished. The size of the glass sample was about $3 \mathrm{~mm} \times$ $3 \mathrm{~mm} \times 3 \mathrm{~mm}$. The compositions of $15 \mathrm{Na}_{2} \mathrm{O} \cdot 85 \mathrm{~B}_{2} \mathrm{O}_{3}$ and $25 \mathrm{Na}_{2} \mathrm{O} \cdot 75 \mathrm{~B}_{2} \mathrm{O}_{3}$ were selected because $\mathrm{Sm}^{2+}$ ions can be easily incorporated into the sodium borate glasses with low sodium contents compared with those with high sodium contents such as $30 \mathrm{Na}_{2} \mathrm{O} \cdot 70 \mathrm{~B}_{2} \mathrm{O}_{3}$ and $35 \mathrm{Na}_{2} \mathrm{O} \cdot 65 \mathrm{~B}_{2} \mathrm{O}_{3} \cdot{ }^{7}$ )

A laser system that generates and amplifies $800 \mathrm{~nm}$ wavelength pulses at a repetition rate of $200 \mathrm{kHz}$ with a pulse width of approximately $120 \mathrm{fs}$ was employed in our study. The laser beam with an average power of $400 \mathrm{~mW}$ was focused on the glass sample through an objective lens (Nikon, $\times 10$ magnification, numerical aperture $\mathrm{NA}=0.30$ ) of the microscope (Nikon, Optiphot 2). After the irradiation for $1 \mathrm{~s}$, a colored spot was formed in the focal point. The diameter of the colored spot was nearly $5 \mu \mathrm{m}$ when transmitted light optical microscope was used. Because of its small size, it was difficult to directly measure the optical properties. Instead, with the help of an XYZ stage, the glass sample was translated at a rate of $10000 \mu \mathrm{m} / \mathrm{s}$ perpendicular to the incident laser beam to produce a colored line with $3 \mathrm{~mm}$ length. Subsequently, $3 \mathrm{~mm} \times 3 \mathrm{~mm}$ arrays of the colored lines at intervals of $10 \mu \mathrm{m}$ were created within the glass sample so that the optical properties were examined.

Optical absorption and photoluminescence spectra were obtained using a spectrophotometer (Hitachi 330) and a fluorescence spectrometer (Hitachi 850), respectively. The photoluminescence spectra were measured using a 514.5 $\mathrm{nm}$ light of an $\mathrm{Ar}^{+}$laser (Spectra Physics, Stabilite 2017) as a light source. For these measurements, we took scans before and after the femtosecond-laser irradiation. All the experiments were carried out at room temperature.

Spectral holes were burned into ${ }^{5} D_{0}-7 F_{0}$ transition of $\mathrm{Sm}^{2+}$ using a Rhodamine 6G dye laser (Spectra Physics 375B, linewidth $\sim 1.3 \mathrm{~cm}^{-1}$ ) pumped by an $\mathrm{Ar}^{+}$laser (Spectra Physics, Beamlok 2060, all lines). A typical laser intensity under the burning was $10 \mathrm{~W} / \mathrm{cm}^{2}$, and the burning time was $300 \mathrm{~s}$. For hole detection, the laser wavelength was scanned, while the fluorescence of ${ }^{5} D_{0}-{ }^{7} F_{2}$ transition of $\mathrm{Sm}^{2+}$, selected with a monochrometer combined with a glass filter, was detected with a photomultiplyer tube (Hamamatsu Photonics, R928). The laser power for reading was $\sim 0.25 \%$ of that for burning. For the measurements below the room temperature, the sample was fixed in a cryogenic refrigerator (Iwatani Plantech, Model CRT-0062000) equipped with a compressor (Iwatani Plantech, Model CA101). In this apparatus, low temperatures can be accomplished by the adiabatic expansion of helium gas supplied by the compressor.

\section{Results and discussion}

Variation in optical absorption spectra of $\mathrm{Sm}^{3+}$-doped $25 \mathrm{Na}_{2} \mathrm{O} \cdot 75 \mathrm{~B}_{2} \mathrm{O}_{3}$ glasses with femtosecond-laser irradiation is shown in Fig. 1(a). The broken and solid curves represent the optical absorption spectra before and after femtosecond-laser irradiation, respectively. The sharp peaks due to $4 f-4 f$ transitions of $\mathrm{Sm}^{3+}$ are observed at 350 to $500 \mathrm{~nm}$ for the unirradiated glass. In addition to these peaks, the irradiation of the glass with femtosecond-laser pulses induces the broad absorption band over the wavelength range of 250 to $800 \mathrm{~nm}$. Color of the glass is colorless and red brown before and after laser irradiation, respectively. The solid curve of Fig. 1(b) shows the absorption effectively induced by laser irradiation. The optical absorption spectrum of thermally reduced glass is shown in
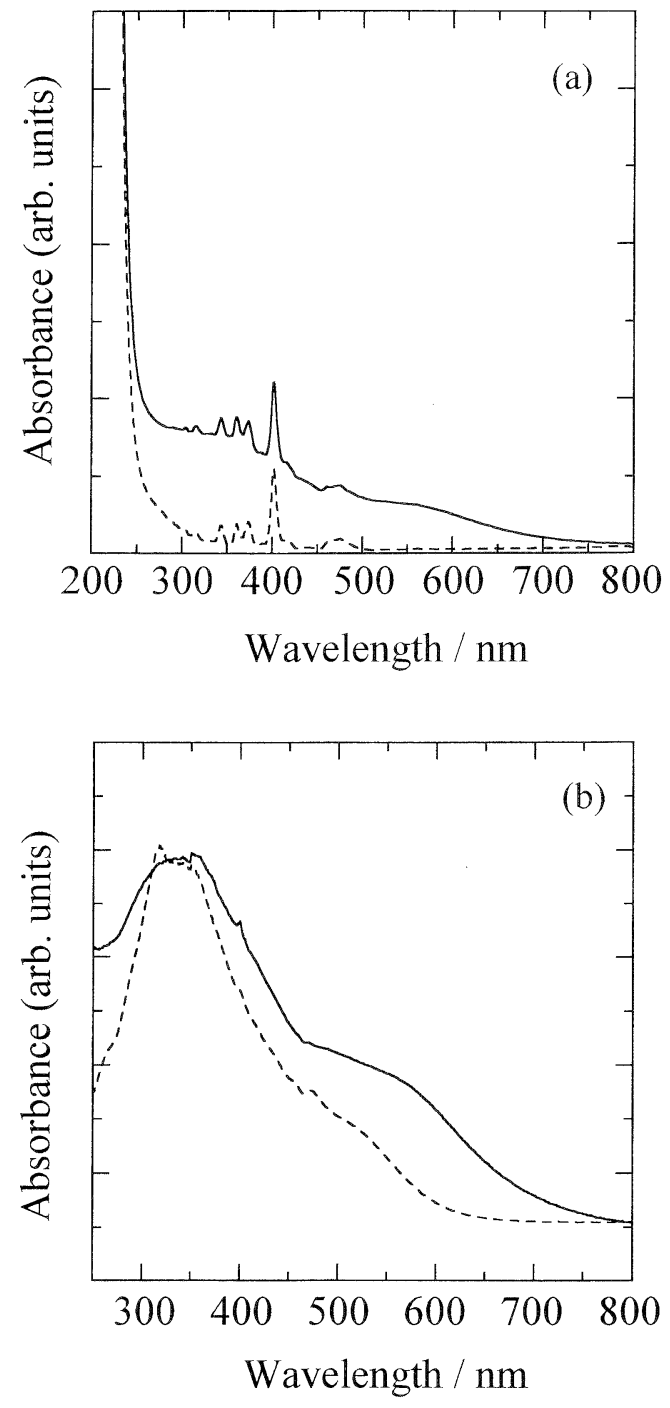

Fig. 1. (a) Variation in optical absorption spectra of $\mathrm{Sm}^{3+}$-doped $25 \mathrm{Na}_{2} \mathrm{O} \cdot 75 \mathrm{~B}_{2} \mathrm{O}_{3}$ glasses with femtosecond-laser irradiation. The solid and broken curves represent before and after femtosecondlaser irradiation, respectively. The measurement was carried out at room temperature. (b) Femtosecond-laser-induced absorption band of $\mathrm{Sm}^{3+}$-doped $25 \mathrm{Na}_{2} \mathrm{O} \cdot 75 \mathrm{~B}_{2} \mathrm{O}_{3}$ glasses (solid curve), which was obtained by subtracting the spectrum of the sample before laser irradiation from that after laser irradiation. The broken curve is optical absorption spectrum of $\mathrm{Sm}^{2+}$-doped $25 \mathrm{Na}_{2} \mathrm{O} \cdot 75 \mathrm{~B}_{2} \mathrm{O}_{3}$ glass prepared by melting in a reducing condition.

the broken curve of Fig. 1(b) for comparison. The broad absorption band at around $350 \mathrm{~nm}$ observed for the thermally reduced glass is attributable to $4 f^{6} \rightarrow 4 f^{5} 5 d$ transition of $\left.\mathrm{Sm}^{2+} .{ }^{7}\right)$ The spectral shape of induced absorption is similar to the absorption band due to $\mathrm{Sm}^{2+}$. A close look at Fig. 1 (b) also reveals that the induced absorption extends to longer wavelength regions compared with the thermally reduced glass. This discrepancy may be ascribed to the creation of point defects by femtosecond-laser irradiation as mentioned below.

Figure 2 shows the variation in emission spectra of $\mathrm{Sm}^{3+}$. doped $25 \mathrm{Na}_{2} \mathrm{O} \cdot 75 \mathrm{~B}_{2} \mathrm{O}_{3}$ glass with femtosecond-laser irradiation. The curves (a) and (b) correspond to the emission spectra before and after femtosecond-laser irradiation, respectively. For the laser-unirradiated glass, the emission peaks due to ${ }^{4} G_{5 / 2} \rightarrow{ }^{6} H_{J}(J=5 / 2,7 / 2,9 / 2)$ transitions of 


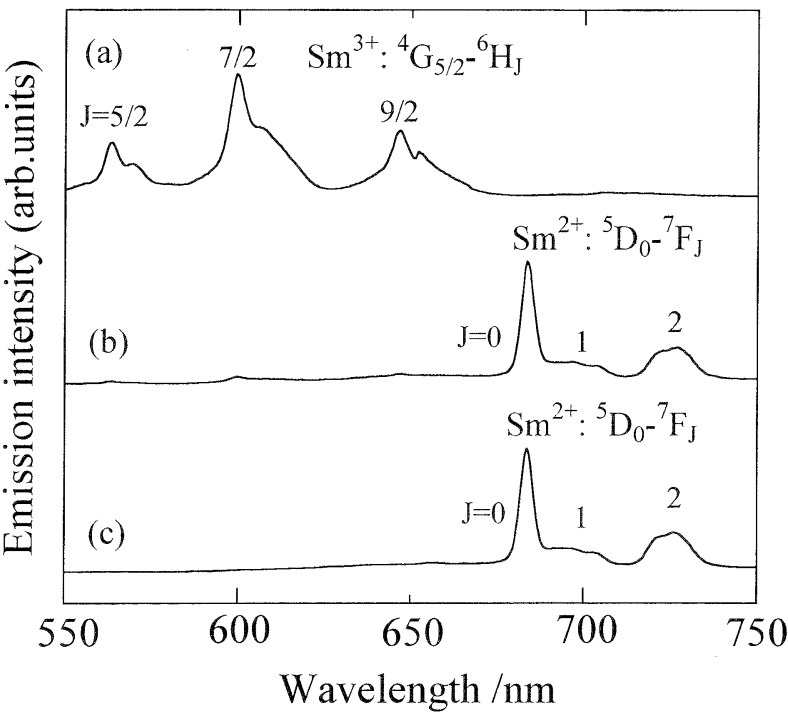

Fig. 2. Variation in emission spectra of $\mathrm{Sm}^{3+}$-doped $25 \mathrm{Na}_{2} \mathrm{O}$ $75 \mathrm{~B}_{2} \mathrm{O}_{3}$ glasses with femtosecond-laser irradiation. The solid curves (a) and (b) represent before and after femtosecond-laser irradiation, respectively. The solid curve (c) shows emission spectrum of $\mathrm{Sm}^{2+}$-doped $25 \mathrm{Na}_{2} \mathrm{O} \cdot 75 \mathrm{~B}_{2} \mathrm{O}_{3}$ glass prepared by melting in a reducing condition.

$\mathrm{Sm}^{3+}$ are observed at 565, 600, and $650 \mathrm{~nm}$, respectively. For the laser-irradiated glass, on the other hand, the emission lines appear at 685,700 , and $725 \mathrm{~nm}$. These peaks are ascribed to ${ }^{5} D_{0} \rightarrow{ }^{7} F_{J}(J=0,1,2)$ transitions of $\mathrm{Sm}^{2+}$, respectively. ${ }^{9)}$ As already reported by Qiu et al.,5),6) this result indicates that the reduction of $\mathrm{Sm}^{3+}$ to $\mathrm{Sm}^{2+}$ can be achieved by femtosecond-laser irradiation. The resultant glass, hereafter, is referred to as photoreduced glass so as to distinguish from thermally reduced glass. In the curve (c) of Fig. 2 is shown the emission spectrum of thermally reduced glass. No apparent difference in the spectral shape was found between photoreduced and thermally reduced glasses.

When $\mathrm{Sm}^{3+}$-undoped $25 \mathrm{Na}_{2} \mathrm{O} \cdot 75 \mathrm{~B}_{2} \mathrm{O}_{3}$ glass is exposed to femtosecond-laser pulses, the optical absorption band shown in Fig. 3 is induced. These spectral features are very similar to those of the identical glass irradiated with X- or $\gamma$-rays. ${ }^{10), 11)}$ This fact implies that the coloration of the glass exposed to near-infrared femtosecond laser pulses is caused by the generation of the same color centers as arising under $\mathrm{X}$ - or $\gamma$-radiation. According to the previous studies, ${ }^{10), 11)}$ the irradiation of sodium borate glass with X-or $\gamma$-rays at room temperature brings about the following reactions which form point defects in the glass;

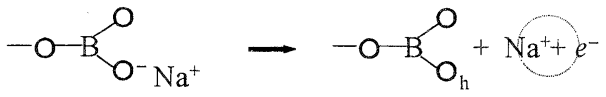

(b)

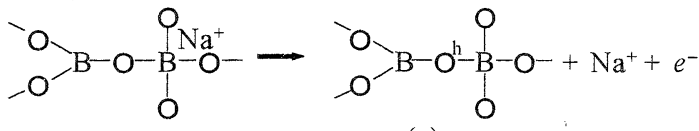

(c)

The defects generated are electrons trapped near $\mathrm{Na}^{+}$ions, non-bridging oxygen hole centers, and hole centers in oxygen bonded to tetrahedrally coordinated boron: These defects give rise to the optical absorption bands indicated by

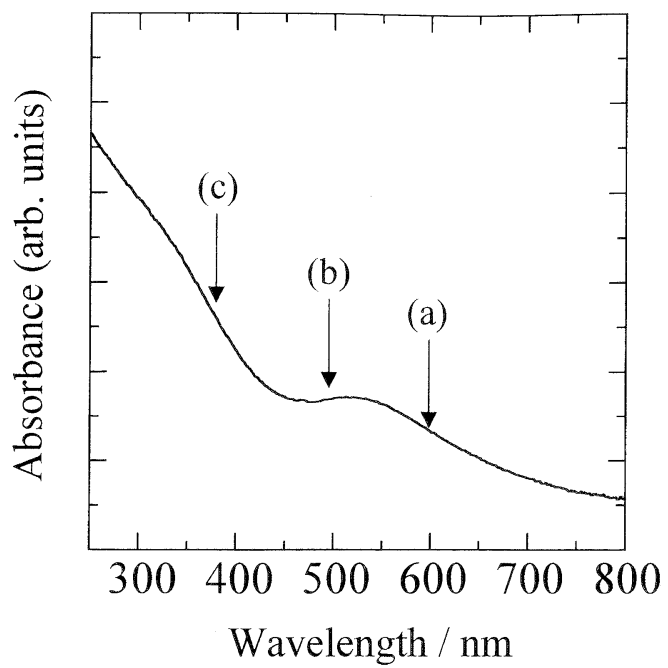

Fig. 3. Spectrum of additional optical absorption of $\mathrm{Sm}^{3+}$-undoped $25 \mathrm{Na}_{2} \mathrm{O} \cdot 75 \mathrm{~B}_{2} \mathrm{O}_{3}$ glasses exposed to femtosecond laser pulses, which was obtained by subtracting the spectrum of the sample before laser irradiation from that after laser irradiation. The absorption bands indicated by (a), (b), and (c) are ascribed to an electron trapped near an $\mathrm{Na}^{+}$ion, a non-bridging oxygen hole center, and a hole center associated with oxygen bonded to tetrahedrally coordinated boron, respectively.

(a), (b), and (c) in Fig. 3, respectively.

In contrast to X-or $\gamma$-rays, the creation of defect centers by near-infrared radiation involves nonlinear optical effects. In previous studies on photoinduced processes of $\mathrm{Sm}^{3+}$ in glasses under near-infrared femtosecond-laser irradiation, multiphoton absorption of near-infrared radiation was considered the mechanism of free-electron generation for avalanche ionization. ${ }^{5), 6)}$ Another plausible process that we believe is single- or two-photon absorption of short-wavelength component of white-light supercontinuum that is generated inside the bulk of glass. ${ }^{12)}$ White-light generation is generally considered to result from the variation of the refractive indices of condensed media induced by high-power femtosecond-laser pulses and the consequent changes in the amplitude, phase, and frequency of the laser beam. These effects induce substantial spectral broadening of the transmitted laser beam in both the long-wavelength and the shortwavelength regions of the spectrum, i.e., white-light generation. The single- or two-photon absorption of shortwavelength component of white-light supercontinuum causes photoionization of glass matrix and the consequent trapping of electrons and positive holes. Following the Reactions (1) and (2), the electrons and positive holes trapped by intrinsic defects produce color centers as shown in Fig. 3. Part of electrons is also captured by extrinsic additives, i.e., $\mathrm{Sm}^{3+}$, resulting in the formation of $\mathrm{Sm}^{2+}$;

$$
e^{-}+\mathrm{Sm}^{3+} \longrightarrow\left(\mathrm{Sm}^{3+}\right)^{-}
$$

Here, $\mathrm{Sm}^{2+}$ is denoted as $\left(\mathrm{Sm}^{3+}\right)^{-}$so as to discriminate from $\mathrm{Sm}^{2+}$ in thermally reduced glass. Thus, the optical absorption due to $4 f^{6} \rightarrow 4 f^{5} 5 d$ transition of $\left(\mathrm{Sm}^{3+}\right)^{-}$, as well as the color center originating from intrinsic defects, yields the effectively induced absorption as shown in Fig. 1(b).

We have performed the measurements of spectral hole burning for photoreduced $\mathrm{Sm}^{3+}$, i.e., $\left(\mathrm{Sm}^{3+}\right)$ - in order to evaluate whether the glass network in the vicinity of the $\left(\mathrm{Sm}^{3+}\right)^{-}$is experiencing a combination of defect formation and structural relaxation. Figure 4(a) shows a typical spectrum of hole burning at $77 \mathrm{~K}$ for $25 \mathrm{Na}_{2} \mathrm{O} \cdot 75 \mathrm{~B}_{2} \mathrm{O}_{3}$ glass. The hole burning of the thermally reduced glass is also shown in 

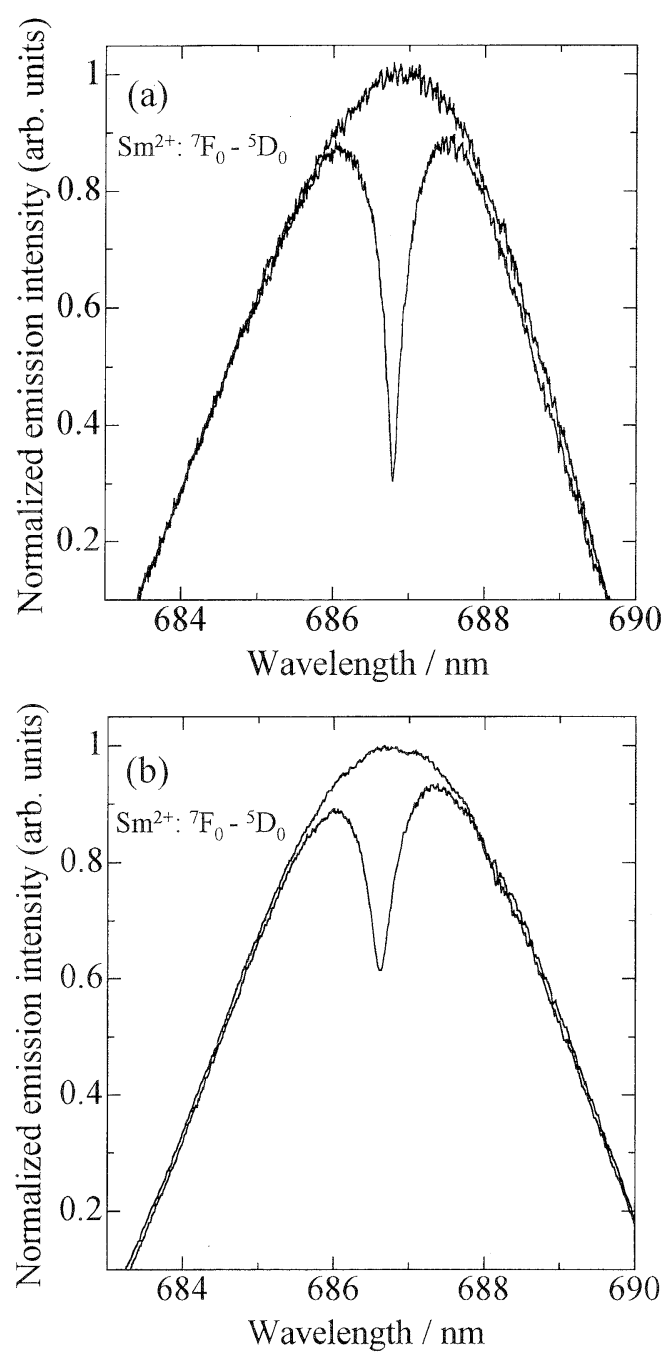

Fig. 4. (a) Hole burning at $77 \mathrm{~K}$ for the ${ }^{5} D_{0}-{ }^{7} F_{0}$ transition of $\mathrm{Sm}^{2+}$ in $25 \mathrm{Na}_{2} \mathrm{O} \cdot 75 \mathrm{~B}_{2} \mathrm{O}_{3}$ glass irradiated with femtosecond-laser pulses. The burning of hole was carried out at the wavelength of $686.8 \mathrm{~nm}$ for $300 \mathrm{~s}$ using a DCM dye laser. (b) Hole burning at $77 \mathrm{~K}$ for the ${ }^{5} D_{0}-{ }^{7} F_{0}$ transition of $\mathrm{Sm}^{2+}$ in $25 \mathrm{Na}_{2} \mathrm{O} \cdot 75 \mathrm{~B}_{2} \mathrm{O}_{3}$ glass prepared by melting in a reducing condition. The hole was burned under the same condition as in (a). Both the hole spectra were obtained by monitoring the emission due to the ${ }^{5} D_{0}{ }^{-7} F_{2}$ transition of $\mathrm{Sm}^{2+}$ before and after laser irradiation.

Fig. 4(b). The comparison between Figs. 4(a) and 4(b) reveals that the spectral hole burning of $\left(\mathrm{Sm}^{3+}\right)$ - is more efficient than that of $\mathrm{Sm}^{2+}$; in the photoreduced glass, a fairly large fraction of the absorption line corresponding to the selected $\left(\mathrm{Sm}^{3+}\right)$ - ions $(\sim 70 \%$ compared with $\sim 40 \%$ in the thermally reduced glass) is lost from the line profile. Similar result was obtained at room temperature for the $15 \mathrm{Na}_{2} \mathrm{O} \cdot 85 \mathrm{~B}_{2} \mathrm{O}_{3}$ glasses, which is shown in Fig. 5 . The curves (a) and (b) correspond to the photoreduced and thermally reduced glasses, respectively. Spectral holes are clearly burned at room temperature. The depth of hole is about twice larger in the photoreduced glass than in the thermally reduced glass.

Hole burning of thermally reduced glasses involves photoionization of $\mathrm{Sm}^{2+}: 7$ )

$$
\mathrm{Sm}^{2+} \stackrel{\hbar \omega}{\longrightarrow} \mathrm{Sm}^{3+}+e^{-}
$$

It is known that the photoionization hole burning is significantly affected by local environment around $\left.\mathrm{Sm}^{2+} .7\right), 13$ )

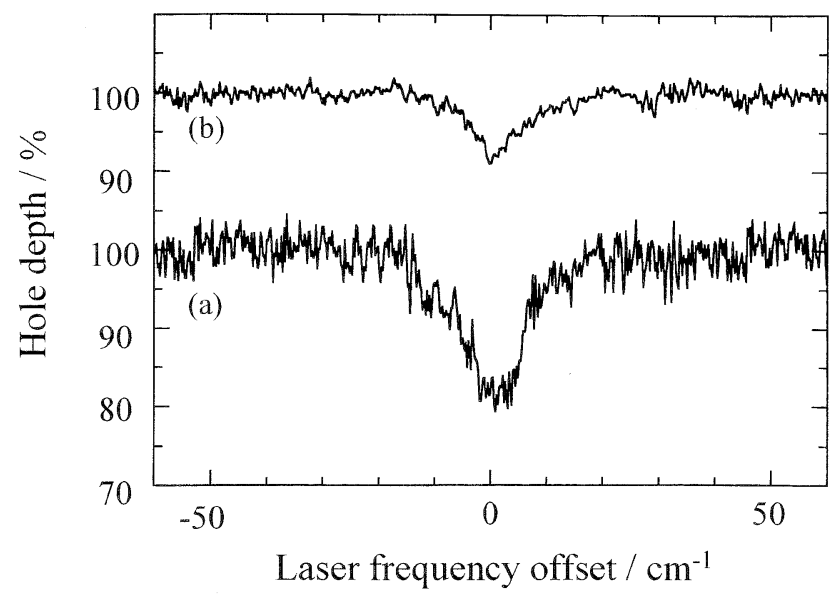

Fig. 5. Room-temperature hole spectra for the ${ }^{5} D_{0}-{ }^{7} F_{0}$ transition of $\mathrm{Sm}^{2+}$ in $15 \mathrm{Na}_{2} \mathrm{O} \cdot 85 \mathrm{~B}_{2} \mathrm{O}_{3}$ glass exposed to femtosecond-laser pulses (a) and $15 \mathrm{Na}_{2} \mathrm{O} \cdot 85 \mathrm{~B}_{2} \mathrm{O}_{3}$ glass prepared by melting in a reducing condition (b). The burning of hole was carried out at the wavelength of $686.8 \mathrm{~nm}$ for $300 \mathrm{~s}$ using a DCM dye laser. Both the hole spectra were obtained by subtracting the excitation spectrum of the sample before laser irradiation from that after laser irradiation.

For instance, in different alkali borate glasses, the depth of hole increases with an increase in the local basicity around $\mathrm{Sm}^{2+}$.7) This is because the higher valence state is favorable for valence alternative ions in the glasses with higher basicity. In such a situation, the photoionization of $\mathrm{Sm}^{2+}$ to $\mathrm{Sm}^{3+}$ takes place more readily. Also, it was found that the irradiation of $\mathrm{Sm}^{2+}$-doped sodium borate glasses with X-rays enhances the hole-burning rate at the $\mathrm{Sm}^{2+}$ sites perturbed by defects such as oxygen hole centers. ${ }^{13)}$ In the present case, the photoreduced $\mathrm{Sm}^{3+}$, i.e., $\left(\mathrm{Sm}^{3+}\right)$ - is metastable compared with $\mathrm{Sm}^{2+}$ formed by the thermal process, since the local structural rearrangement following femtosecond-laser irradiation is not plausible in the rigid state near room temperature. In other words, $\left(\mathrm{Sm}^{3+}\right)^{-}$in Reaction (3) can be regarded as the higher energy state, owing to its excess negative charge. This state is partly relaxed by photoionization of $\left(\mathrm{Sm}^{3+}\right)$ - to $\mathrm{Sm}^{3+}$ according to Reaction (4), which contributes to more efficient hole burning. Electrons generated by the ionization transfer to nearby traps with spectral holes being formed. The predominant centers that act as the electron traps are oxygen hole centers as described in Reactions (1) and (2). In photoreduced glasses, thus, the hole burning may occur by the optically activated recombination of the electron released from $\left(\mathrm{Sm}^{3+}\right)^{-}$with the oxygen hole center. We propose that the incomplete structural relaxation around photoreduced $\mathrm{Sm}^{3+}$, i.e., $\left(\mathrm{Sm}^{3+}\right)^{-}$and the formation of oxygen hole centers are responsible for the efficient photoionization hole burning.

$\mathrm{Sm}^{2+}$-doped borate glasses show photon-gated hole burning, i.e., hole burning that occurs only in the presence of both wavelength-selective and gating-light beams;7) twostep photoionization of $\mathrm{Sm}^{2+}$ occurs only in the part where the two light beams overlap with each other. By use of focused femtosecond-laser pulses, on the other hand, it is possible to induce the photoreduction of $\mathrm{Sm}^{3+}$ to $\mathrm{Sm}^{2+}$ with micrometer precision inside a transparent glass. The combination of both effects thus offers interesting possibilities from a practical viewpoint, one being wavelength- and space-selective optical memory.6) 


\section{Conclusions}

Photoinduced valence changes of samarium ions were examined for binary sodium borate glasses. Electron-trapped $\mathrm{Sm}^{3+}$, i.e., $\mathrm{Sm}^{2+}$, oxygen hole centers, and electrons trapped near $\mathrm{Na}^{+}$are formed by the irradiation of $\mathrm{Sm}^{3+}$ doped sodium borate glasses with $800 \mathrm{~nm}$ femtosecondlaser pulses. Photoionization hole burning on the ${ }^{5} D_{0}-{ }^{7} F_{0}$ transition of $\mathrm{Sm}^{2+}$ was observed at $77 \mathrm{~K}$ to room temperature using a DCM dye laser for the glasses exposed to femtosecond-laser pulses and the glasses prepared by melting in reducing conditions. The efficiency of hole burning is about twice higher for $\mathrm{Sm}^{2+}$ produced by the photoinduced process than for $\mathrm{Sm}^{2+}$ formed by the thermal process. The observed phenomenon can be related to the metastable $\mathrm{Sm}^{2+}$ ions and oxygen hole centers induced by femtosecondlaser pulses. It is suggested that the efficient photoionization hole burning takes place as s result of photostimulated recombination of the electrons trapped by $\mathrm{Sm}^{3+}$ with the oxygen hole centers.

Acknowledgment This work is financially supported by the Nippon Sheet Glass Foundation. The authors would like to thank Dr. J. Qiu and Dr. J. Si of Photon Craft Project, Japan Science and Technology Corporation, for experiments of the femotosecondaser irradiation.

\section{References}

1) Devis, K. M., Miura, K., Sugimoto, N. and Hirao, K., Opt.
Lett., 21, 1729-31 (1996).

2) Miura, K., Qiu, J., Inouye, H., Mitsuyu, T. and Hirao, K., Appl. Phys. Lett., 71, 3329-31 (1997).

3) Glezer, E. N., Milosavljevic, M., Hung, H., Finalay, R. J., Her, R. H., Callan, J. P. and Mazur, E., Opt. Lett., 21, 2023-25 (1996).

4) Watanabe, M., Sun, H.-B., Juodkazis, S., Matsuo, S., Misawa, H., Miwa, M. and Kaneko, R., Appl. Phys. Lett., 74, 3957-59 (1999).

5) Qiu, J., Miura, K., Suzuki, T., Mitsuyu, T. and Hirao, K., Appl. Phys. Lett., 74, 10-12 (1999).

6) Qiu, J., Miura, K., Nouchi, K., Suzuki, T., Kondo, K., Mitsuyu, T. and Hirao, K., Solid State Commun., 113, 341-44 (2000).

7) Cho, D. H., Hirao, K. and Soga, N., J. Non-Cryst. Solids, 189, 181-90 (1995).

8) Cho, D. H., Hirao, K., Fujita, K. and Soga, N., J. Am. Ceram. Soc., 79, 327-32 (1996).

9) Fujita, K., Tanaka, K., Hirao, K. and Soga, N., J. Appl. Phys., 81, 924-30 (1997)

10) Bishay, A., J. Non-Cryst. Solids, 3, 54-114 (1970).

11) Maekawa, T., Uchida, H., Iwano, E. and Yokokawa, T., J. Ceram. Soc. Japan (Yogyo-Kyokai-Shi), 92, 398-404 (1984) [in Japanese].

12) Efimov, O. M., Gabel, K., Garnov, S. V., Glebov, L. B., Grantham, S., Richardson, M. and Soeileau, M. J., J. Opt. Soc. Am. $B, 15,193-99$ (1998).

13) Cho, D. H., Hirao, K., Tanaka, K. and Soga, N., J. Lumin., 68, 171-78 (1996). 